\title{
Regeneron revisits genomics
}

\section{By Chris Cain, Senior Writer}

Regeneron Pharmaceuticals Inc. has opened a new genetics center tasked with analyzing the genomes of at least 100,000 Geisinger Health System patients in the next 5 years. The company hopes the volume of data, diversity of the patient population and rapid validation in humanized mouse models will yield more actionable opportunities than earlier sequencing efforts.

Regeneron is the latest company to enhance in-house commitments to genomics-guided drug discovery as the cost of whole-genome sequencing falls and throughput improves. Another example is Amgen Inc.'s December 2012 acquisition of deCode genetics ehf for $\$ 415$ million in cash. ${ }^{1}$

"This is genomics the second time around," Regeneron CSO George Yancopoulos told SciBX. "During the genomics bubble of 2000, there was premature excitement and hype, but we emphasized the need for functional genetic studies in mice and did not think direct human sequencing would be a large tool for drug discovery."

Indeed, in a September 2000 interview with BioCentury, ${ }^{2}$ he extolled the functional approach. "We are amazed at the amount of information that's been generated, but that is the easy part. The difficult part is translating that into valuable targets. There is no way of automating the scientific process. Traditional genomics has not yet led to a major scientific discovery that provides insight about a disease," he said.

"What has changed since then," Yancopoulos told SciBX last week, "is that the technology has improved exponentially." He also noted that low throughput genomics studies from academic teams have driven many drug discovery efforts, including two that were directly relevant for Regeneron.

An early genomics study identified and characterized mutations in NLR family pyrin domain containing 3 (NLRP3; NALP3; CIAS1) as the cause of cryopyrin-associated periodic syndromes (CAPS). That finding led to the development of Regeneron's first marketed product, the IL-1 trap Arcalyst rilonacept.

More recent academic studies linked proprotein convertase subtilisin/ kexin type 9 (PCSK9) mutations to hypercholesterolemia and led to the development of PCSK9-targeting drugs.
At least 10 companies are developing inhibitors of the target, and Regeneron and partner Sanofi have the anti-PCSK9 mAb alirocumab in 12 Phase III studies.

Yancopoulos said that the ability to perform large-scale, whole-exome and whole-genome sequencing and automate the process was one reason that the time was right to reinvest in a genomics discovery effort. Indeed, the day after Regeneron and Geisinger launched their initiative, Illumina Inc. introduced the first system capable of sequencing whole human genomes for less than $\$ 1,000$.

Regeneron did not disclose the technology its sequencing center will use but did say it will use a combination of whole-exome and wholegenome technologies, as whole-exome sequencing is still substantially less expensive.

The center will be operated as a wholly owned subsidiary of Regeneron named Regeneron Genetics LLC. To lead its sequencing operations, the company hired John Overton, who previously was associate director of the Yale University Center for Genome Analysis.

To lead informatics, the company hired Jeffrey Reid, who was formerly an assistant professor at the Human Genome Sequencing Center at the Baylor College of Medicine.

Yancopoulos said that the partnership with Geisinger was another key to the new initiative. "We wanted to study a large population that had an outstanding commitment to electronic health records, long-term follow-up of individual patients and generations of data. We identified them as the best and perhaps only right collaborator for this effort-and they have about three million residents in their health system."

Geisinger owns 41 hospitals and clinics in central and northeastern Pennsylvania and is also an insurer. The system has transitioned from a fee-for-service model to a performance-

based accountable care model over the last several years, as described in an interview with Glenn Steele, president and CEO of Geisinger, on "BioCentury This Week".

Regeneron will obtain de-identified genetic data and health information through the collaboration and is covering the costs for Geisinger. "We are not paying them, and they are not profiting. This is two like-minded institutions working together at cost," Yancopoulos said.

He said that the Geisinger patients will provide a much greater diversity of genetic information than prior population studies, such as those from deCode. "The Icelandic population is tapped, and it has limited genetic diversity due to founder effects," he said.

$\mathrm{He}$ added that Regeneron has different goals than deCode. "We have enormous admiration for deCode; we think they were on the right track. But what differentiates us is a matter of focus and direction. Because they were not a therapeutics company, it was easy and exciting to publish academic publications. By combining the genomics approach with laboratory approaches, I think the number or fraction of actionable discoveries will increase," said Yancopoulos.

He specifically highlighted Regeneron's VelociGene knockout mouse 


\section{ANALYSIS}

platform as an example of how the company can rapidly test the effects of putative disease alleles.

Yancopoulos expects 100,000 patients to be sequenced within 5 years, but he did not disclose a timeline or specific benchmarks for when the results will inform Regeneron's discovery stage pipeline.

According to Yancopoulos, the project is the largest planned sequencing effort to date in the U.S., and he noted that a U.K. plan to sequence and analyze the genome of 100,000 NHS patients is years away.

The Regeneron Genetics Center also has collaborations with the NIH and the National Human Genome Research Institute as part of the Undiagnosed Diseases Program and is open to additional collaborations.

Cain, C. SciBX 7(3); doi:10.1038/scibx.2014.75

Published online Jan. 23, 2014

\section{REFERENCES}

1. McCallister, E. BioCentury 20(51), A1-A4; Dec. 24, 2012

2. Bernstein, K. BioCentury 8(39), A1-A7; Sept. 5, 2000

3. McCallister, E. BioCentury 21(3) A6-A7; Jan. 20, 2014

COMPANIES AND INSTITUTIONS MENTIONED

Amgen Inc. (NASDAQ:AMGN), Thousand Oaks, Calif.

Baylor College of Medicine, Houston, Texas

Geisinger Health System, Danville, $\mathrm{Pa}$.

Illumina Inc. (NASDAQ:ILMN), San Diego, Calif.

National Health Service, London, U.K.

National Human Genome Research Institute, Bethesda, Md.

National Institutes of Health, Bethesda, Md.

Regeneron Pharmaceuticals Inc. (NASDAQ:REGN), Tarrytown, N.Y. Sanofi (Euronext:SAN; NYSE:SNY), Paris, France

Yale University, New Haven, Conn. 